\title{
A COMPUTERIZED ELECTRONIC CENSUS ENUMERATION PLATFORM
}

\author{
Horsfall, Otelemate $M^{1}$, Kamalu, Ugochukwu $A^{2}$, Nwazor, Nkolika $O^{3}$ \\ ${ }^{1}$ Department of Electrical/Electronic Engineering, University of Port Harcourt, Rivers State, Nigeria \\ ${ }^{2}$ Department of Electrical/Electronic Engineering, University of Port Harcourt, Rivers State, Nigeria \\ ${ }^{3}$ Department of Electrical/Electronic Engineering, University of Port Harcourt, Rivers State, Nigeria
}

\begin{abstract}
This paper presents a computerized Electronic Census Enumeration Platform design. It gives a detailed design approach in the development of a census enumeration platform that ensures accurate and real time operation. Accurate census data is essential to the growth and development of any nation. However, the collection of this data has been a herculean task to the government owing to the available manual paper forms method employed. This method, the canvasser method is flawed with many errors, intentionally or otherwise, and challenges, ranging from the delay in the release of results, manipulation and falsification, double registration, security and integrity of data as well as a huge financial cost in the employment of many ad hoc staff and in the printing of bulky paper forms. This paper leverages on the rapid growth in technology to adopt a smarter, reliable and advanced method of census data collection, capture and data analysis. The system employed the use of an electronic form developed using the software program C\#, a database created using a Relational Database Management System (RDBMS) Microsoft SQL and incorporates a biometric fingerprint scanner which adds security and authentication to the system. The scanner generates a biometric encryption (BE) key which is distinct to every individual and is securely bound to the finger print image of an individual. The result showed an improved method of census data collection and security as well as a quicker way of doing analysis which supports the timely release of results, a departure from the past.
\end{abstract}

Keywords: Census, Biometric, Fingerprint, Biometric Encryption, SQL, C\# ****

\section{INTRODUCTION}

The knowledge of the population of any nation is very critical to its development. Census is one of the very vital statistical information needed by a country for effective planning and deployment of resources for growth and development.

Census is the systematic procedure of acquiring and recording information about the members of a given population [1]. Before now, the only available method of collection of census data was the use of paper questionnaires or forms, which is termed the canvasser method. This method was plagued with so many flaws and human errors, ranging from the manipulation and falsification of results, double or multiple registration, employment of many ad hoc staff, printing of bulky paper forms, enormous task of capturing the information from the forms and doing the necessary statistical analysis, hence the delay in the release of census result sets in. Data integrity is also greatly compromised using this method, as data is vulnerable to attack by moths, rodents, ants, robbers, as well as, being at the mercy of a fire disaster, while occupying a large office space.In Nigeria, for example, the release of census result can take up to a period of two years due to the underlining challenges. Census results are crucial in Nigeria as they are used politically to determine state creation, resource allocation and wards delineation etc. Hence, an incoherent census result has at several times led to litigations by various state governments and regions, aimed at correcting the anomaly.As the world of technology continues to grow, rapidly affecting every sphere of life, there is the need to adopt it in this area. To overcome these challenges a computerized electronic census enumeration platform with biometrics is proposed as a solution. A computerised enumeration system is a software system developed for the collection of census data. It eliminates and eases the rigorous process of data collection in a census and helps to smartly generate census results and statistical analysis of the census data. The biometrics adds both privacy of data and security to the system while authenticating the user.

\section{METHODOLOGY}

\subsection{Data Collection}

Data was collected randomly, conducting census on some selected people around the Rumuolumeni vicinity, in Obio Akpor Local Government Area of Rivers state, Nigeria. About 25 individuals were counted, for a start, with the system, to determine its operational efficiency, and obtained result was encouraging.

\subsection{System Design}

The platform is made up of two major parts, the hardware components and the software components. The hardware components were not designed for the system. The system block diagram is shown in figure 1. 


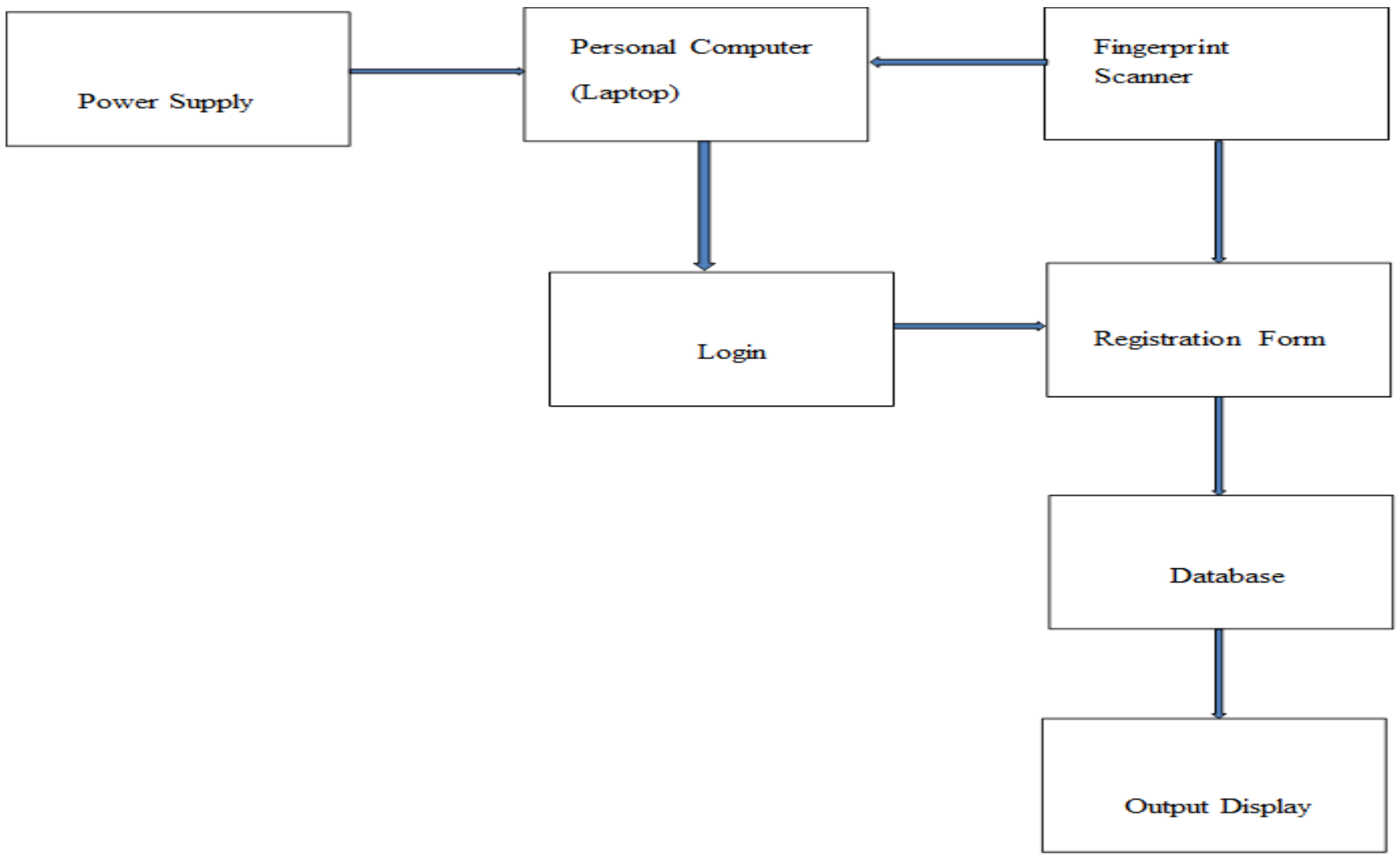

Fig 1: System block diagram.

\section{Hardware Components}

These are the tangible and physical parts that supports and enhance the system workings. It consists of the Power Supply Unit, the Processing Unit (Laptop PC) and the Biometric Fingerprint Scanner.

Power Supply Unit: Power supply will normally be obtained from the public utility supply grid. In Nigeria the supply voltage for household electronics is a 2 wire single phase voltage of $230 \mathrm{v}$ at a frequency of $50 \mathrm{~Hz}$. In the absence of supply from the national grid, a contingency plan of $24 \mathrm{v}, 3000 \mathrm{mAh}$ (and above) DC rechargeable Li-ion battery pack is provided to supply the needed power to the system.

Processing Unit: The processing unit is personal laptop computer (PC).The computer system used is HP EliteBook, an Intel ${ }^{\circledR}$ Core $^{\mathrm{TM}}$ i5-2540M with a processing frequency of $2.60 \mathrm{GHz}$ and installed RAM of $4 \mathrm{~GB}$ and a storage capacity of 232GB, 64-bit computing with rated memory speed of 1333MHz. The PC houses the database and run the algorithm of the application GUI.

Biometric Fingerprint Scanner: For the purpose of this project I have adopted the DigitalPersona U.are.U 4500 finger print scanner. It is an optical USB 2.0 scanner, supporting Microsoft windows (32-bit and 64 bit) and Linux (32-bit and 64-bit), with an optical sensor resolution of 512ppi, image capture area of $15 * 18 \mathrm{~mm}\left(0.6^{\prime \prime} * 0.7^{\prime \prime}\right)$ with blue LEDS and operating temperature of $0^{\circ} \mathrm{c}$ to $+40^{\circ} \mathrm{c}$. it is most suitable for common or shared computer environments, reliable performance even with dry, moist, or rough fingerprints, excellent image quality, rugged construction as well as easy to install and use. The scanner is connected to the computer via its USB serial port connection.

\section{Software Requirements}

These are the systems software that allows the system run smoothly and communicate with the end user program. Four (4) basic modules make up the census management system. They are 1. Login module. 2. Administration module. 3. Registration form module and 4. Database module 


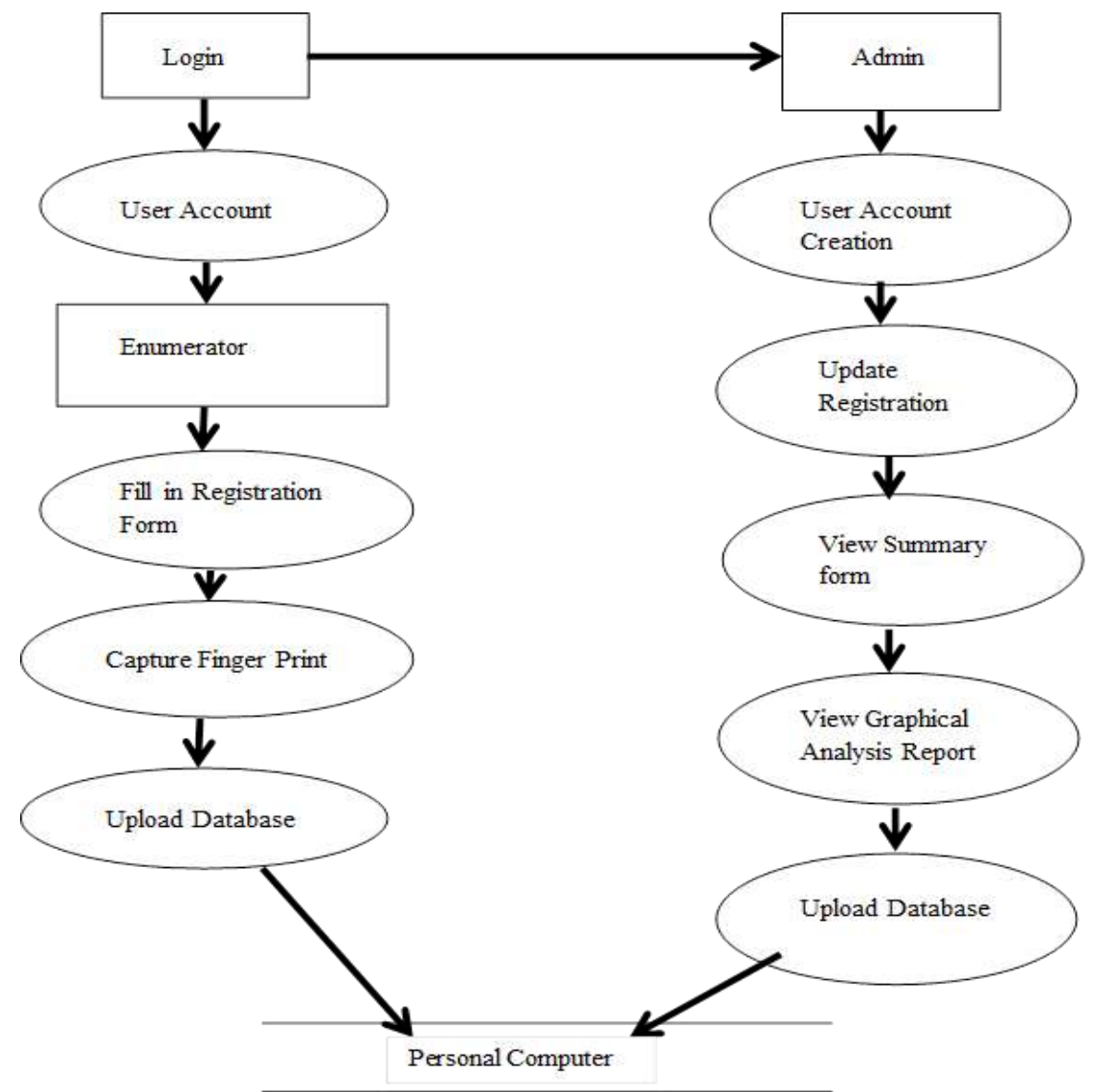

Fig 2: Data Flow Diagram

Login Module: It is the first module of the system. It creates authentication and Authorization for a user and clear access to the registration form with the provision of the correct username and password. A click on this app opens up a login page to the census enumeration platform. Enumerator enters a username and password and on clicking the LOGIN button, the entered data is processed, with the login result displayed either successful or unsuccessful (incorrect username or password). An incorrect login details deny the person access to the capture form. A login successful leads to another input subsystem which is the registration form.

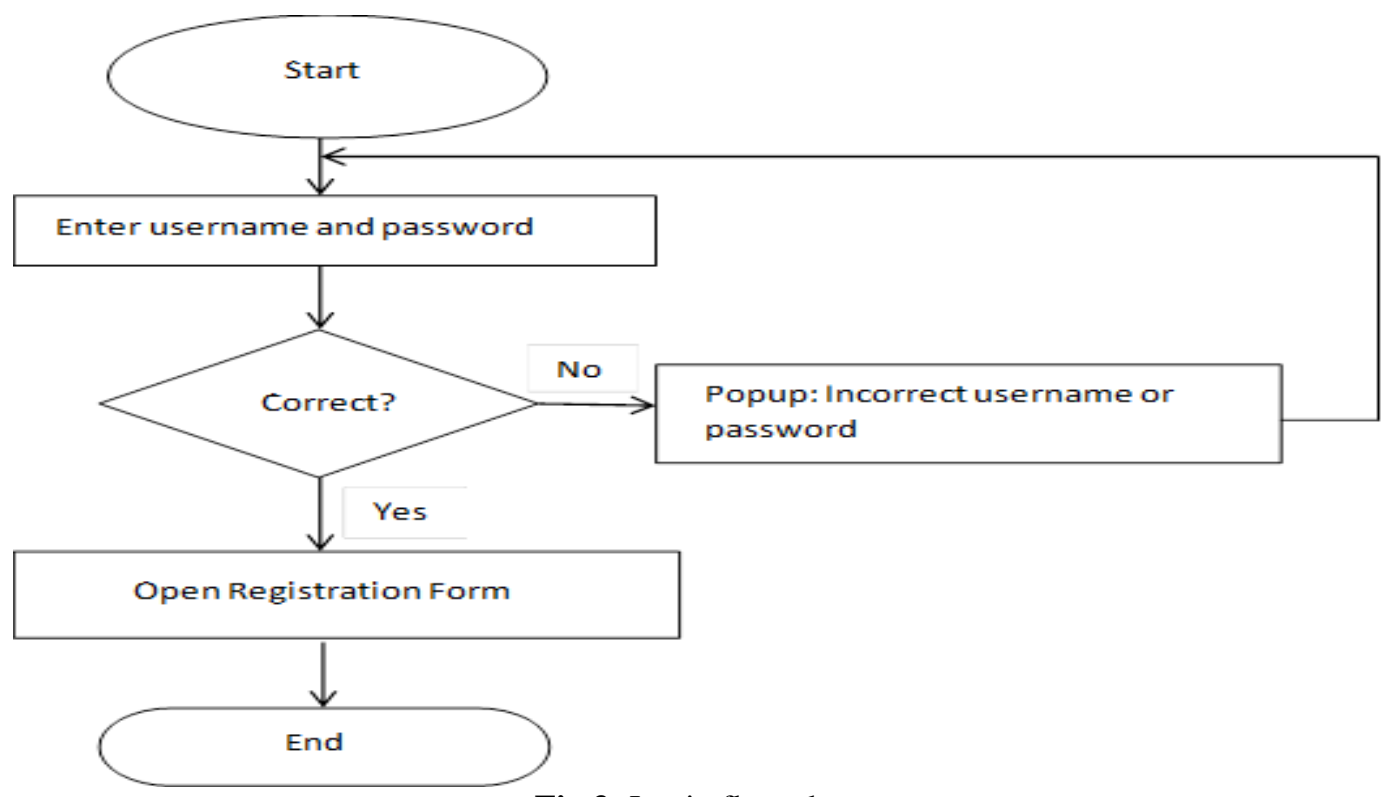

Fig 3: Login flow chart 
Administration Module: The administrator oversees the entire census process as it relates to this platform. He mandates the enumerator to work. He has the power to create or delete user account of an employee, view census graphical analysis report, view summary report and edit or delete census data from the census database etc.

Registration Form Module: An authenticated user finds access to the registration form. This form is used to collect very vital details of a registrant as it relates to census enumeration. With the use of the appropriate Application
Programming Interface (API), the biometric fingerprint scanner is linked to the e-form where fingerprint capture can be done. The biometric fingerprint scanner verifies the registrants' fingerprint with those already in the database. This validation process is termed $1: \mathrm{N}$, that is, one is-to many. If the fingerprint matches anyone existing in the database, registration is denied, otherwise the registrant proceed to give his/her vital information to the enumerator to be captured. This done, the data is now stored to the database.

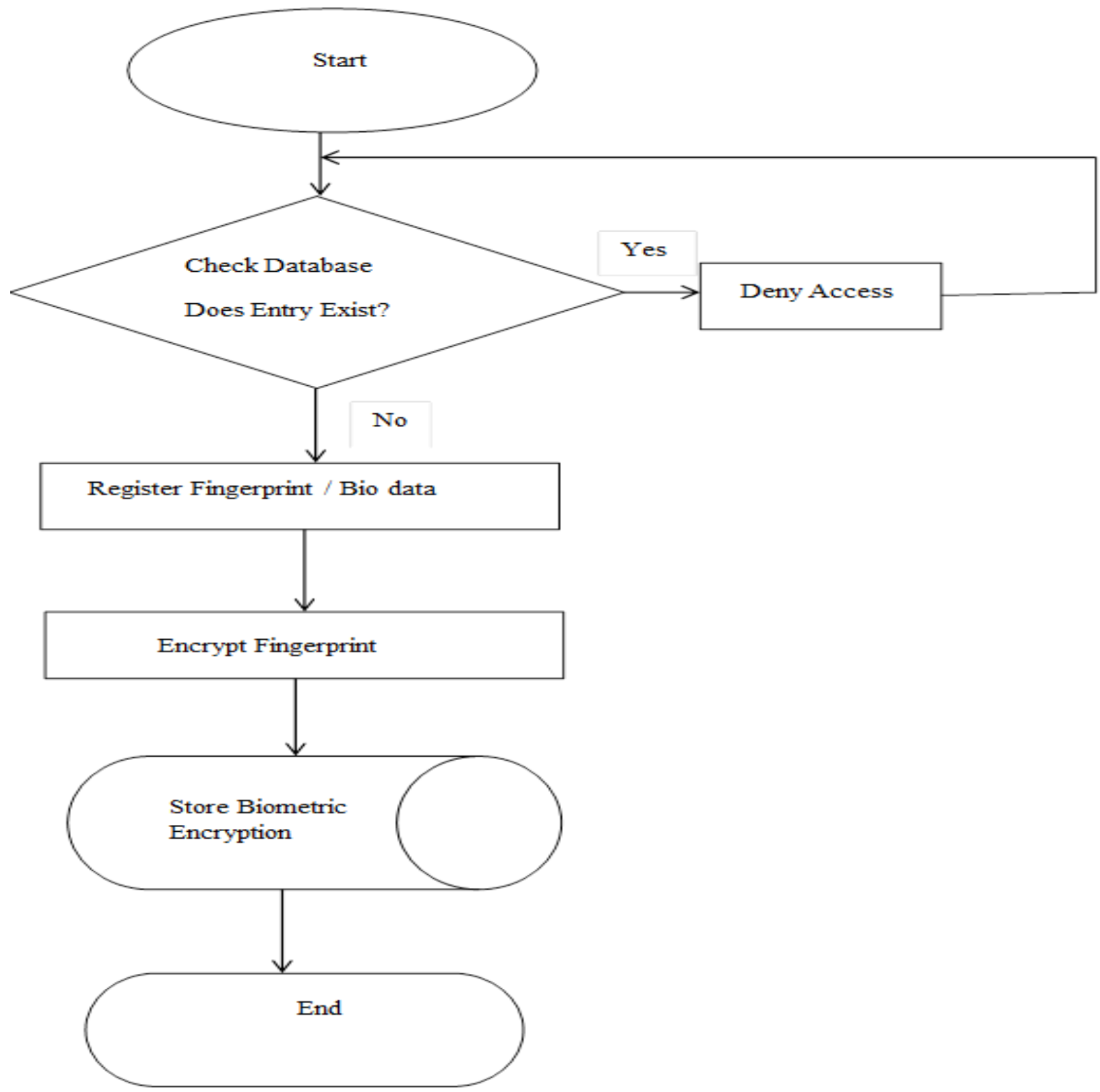

Fig 4: Flowchart for registration form module

Database Module: This platform made use of a relational database management system (RDBMS) in its database design. Different tables are created where data is stored and relations established using primary keys or others known as foreign keys. This system makes use of the existing database system provided by the Microsoft windows local database system. The database is implemented using Microsoft SQL server. 


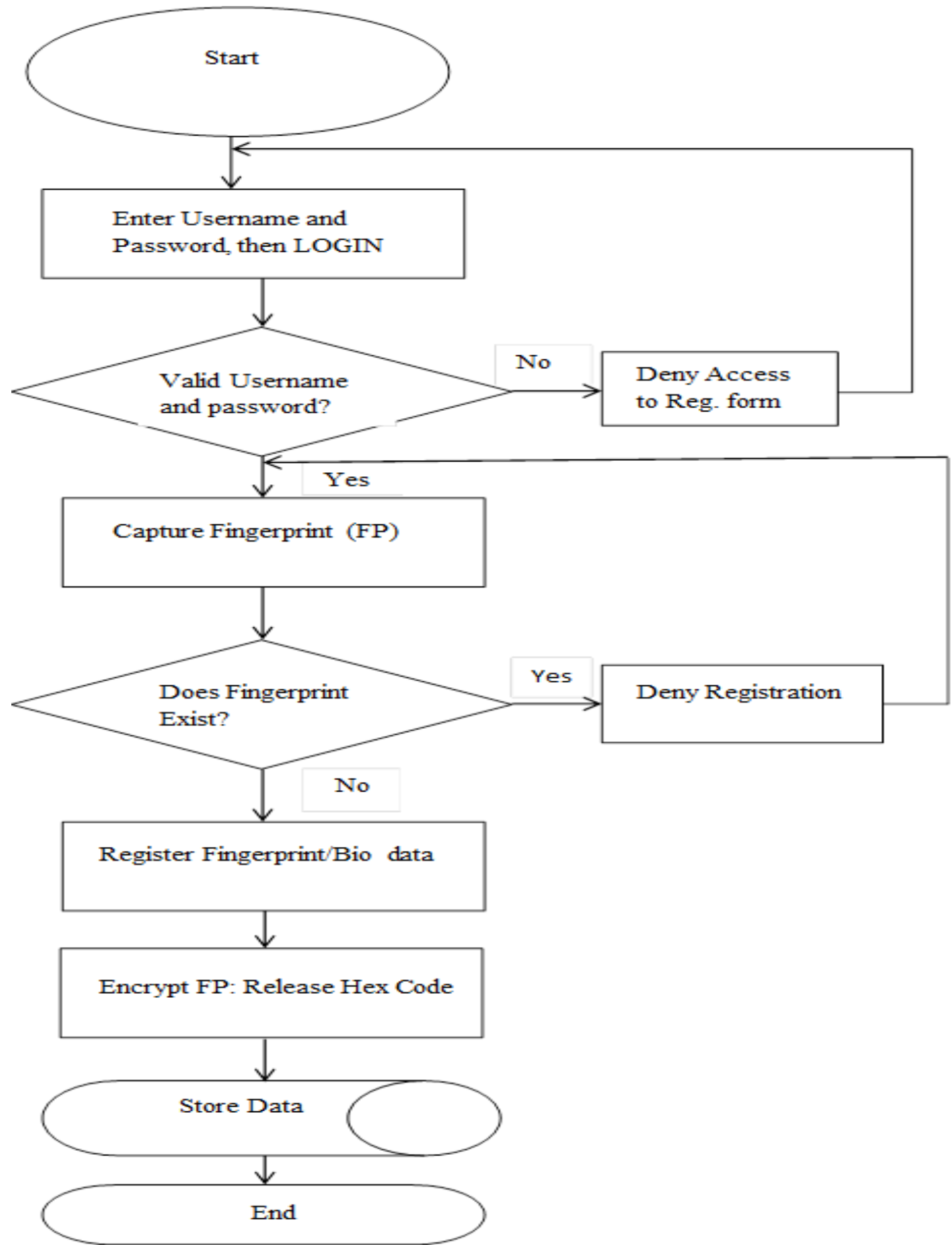

Fig 5: Complete System flowchart

\section{Coding}

SQL: Structured Query Language is a database computer programming language designed for managing data in relational database management systems (RDBMS). Lots of different database systems exist. Some of which are Microsoft SQL Server, Oracle, MySQL, Microsoft access, IBM DB2, Sybase, etc. It is a nonprocedural language which was developed by IBM in the late 1970's.
C\#: C\# is a high-level, modern object-oriented, general purpose programming language similar to Java and C++, created and developed by Microsoft together with the .Net platform.There are highly diverse software's developed with C\# on the .NET platform, examples are, office applications, web applications, websites, desktop (windows) applications, mobile applications, games etc.C sharp (C\#) was used for the implementation for the system design. 


\section{RESULTS AND ANALYSIS}

The design implementation of this system is in two parts. First is the bio-data and fingerprint capture, implemented using C\# Microsoft studio 2010, while the second has to do with the storage of the bio-data and fingerprint, implemented with the Microsoft SQL.

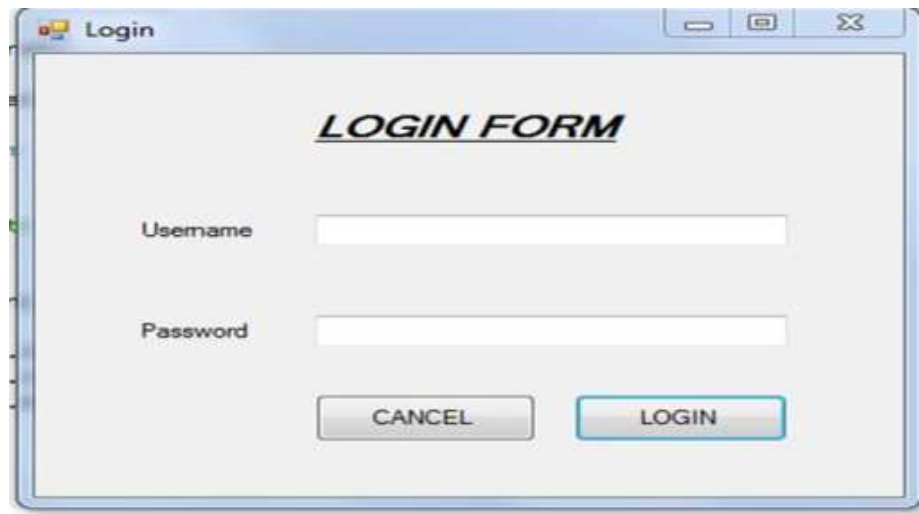

Fig 6: Admin login page
The login page is the first page of the system. It gives access to the system with the provision of the correct username and password, an enumerator/administrator with the correct login details accesses the registration page. An incorrect login detail denies anyone further access into the system and outputs a pop up message "incorrect username or password".

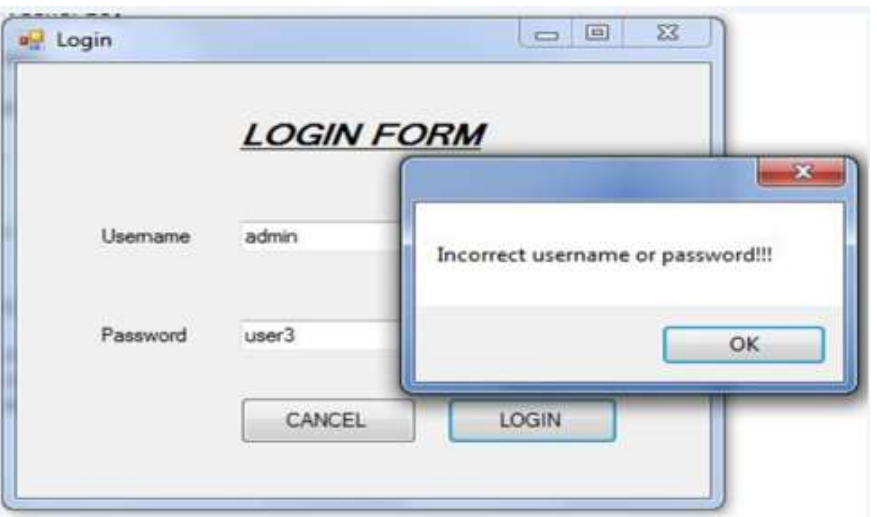

Fig 7: Login fail output

At the input of the correct login details, access is granted to the registration page or form, which captures the bio-data and fingerprint of a registrant. All fields are manually entered by the enumerator and the fingerprint is captured before storage to the database.

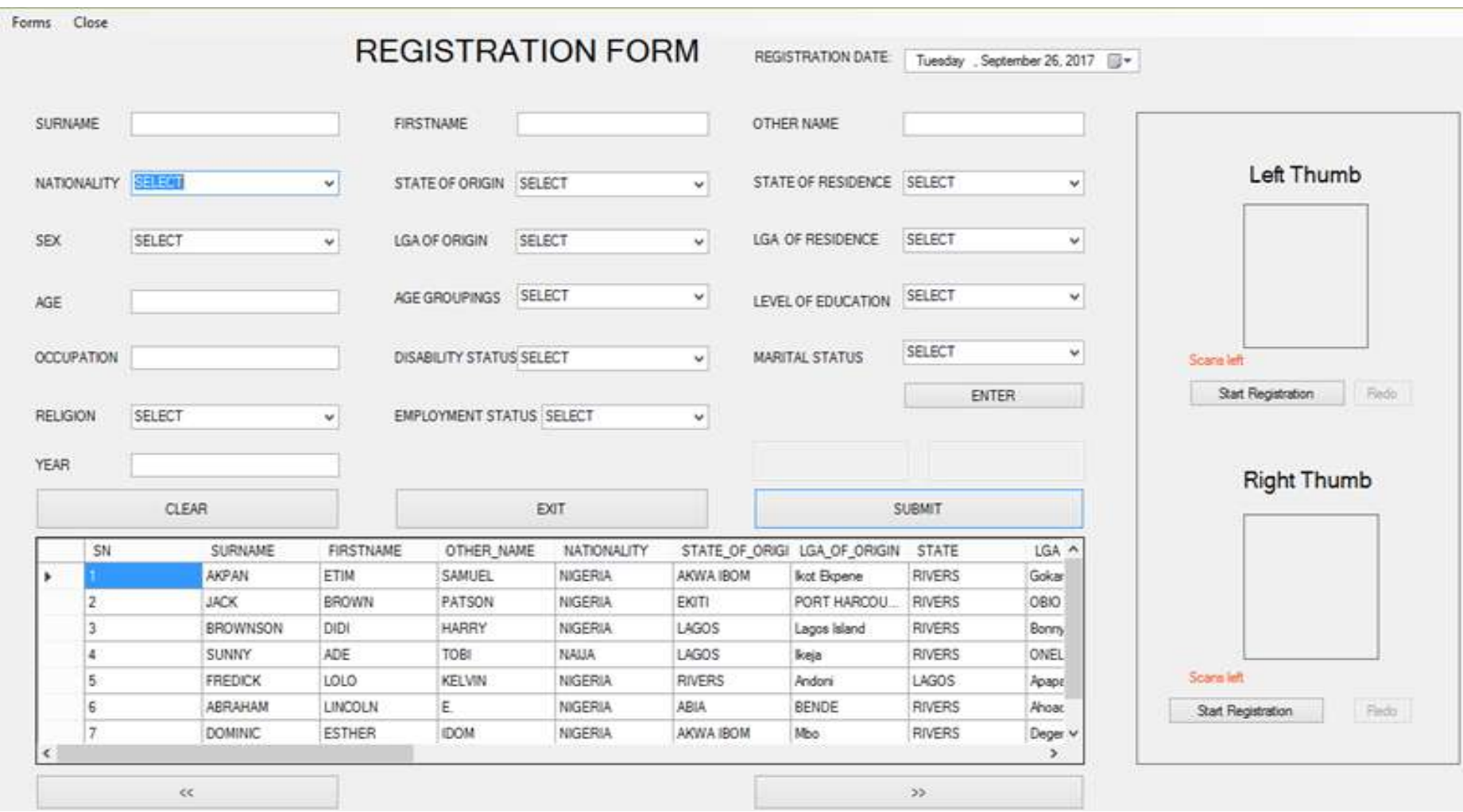

Fig 8: The Registration form

The fingerprint is scanned, captured and encrypted in a unique way by collecting four (4) different variations of the finger (either right or left thumb). The matching process (with the database) allows the system to authenticate the person. A complete scan, matching and authentication generate a unique hexadecimal key corresponding to the encrypted data of the fingerprint image. Authentication fails if user's fingerprint is already registered in the database, thus access is denied to save to the database. 


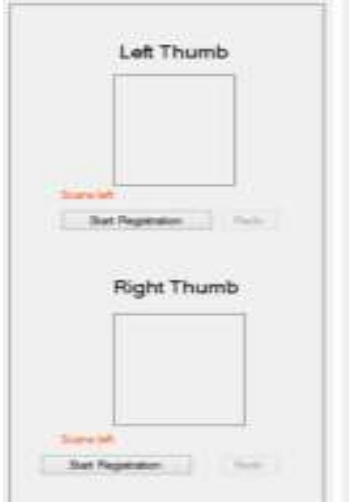

Fig 9: Fingerprint capture template

The system also includes an update registration page, where updates to wrongly entered bio-data information can be corrected. This however, does not affect the fingerprint which cannot be changed. A summary page is also provided

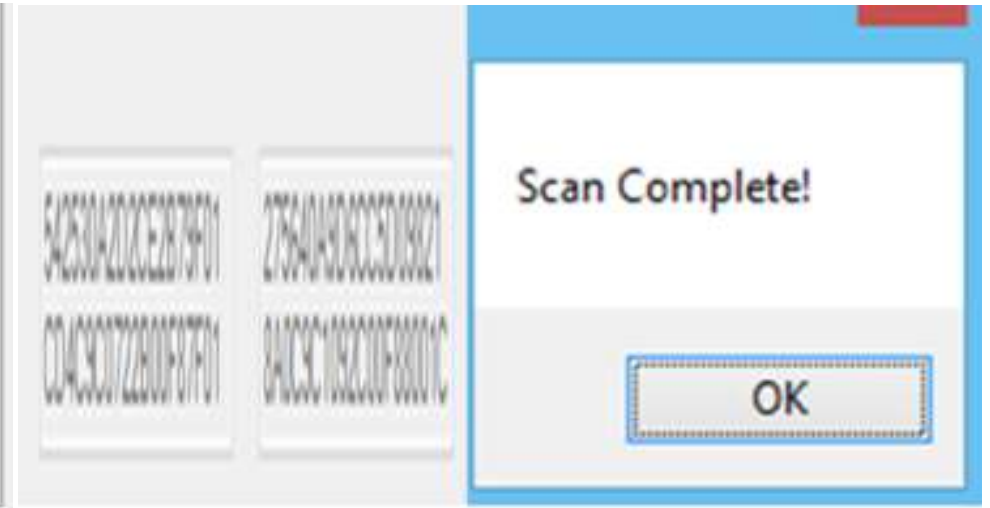

Fig 10: Generated hexadecimal unique code to each thumb and scan complete pop up.

for searching or querying of the database to obtain instant filteredresults. Figures 18 and 19, shows the update and summary forms respectively.

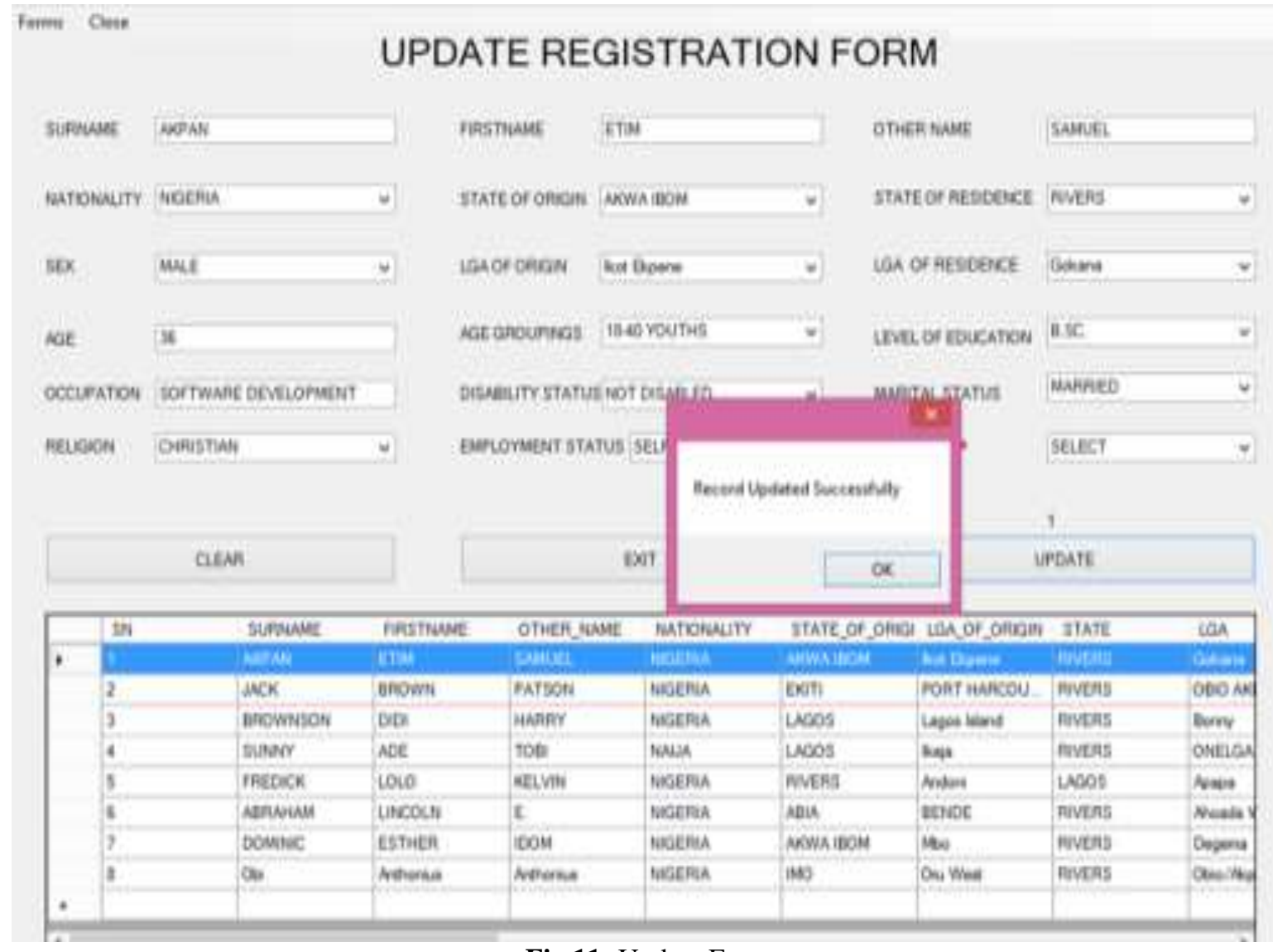

Fig 11: Update Form 


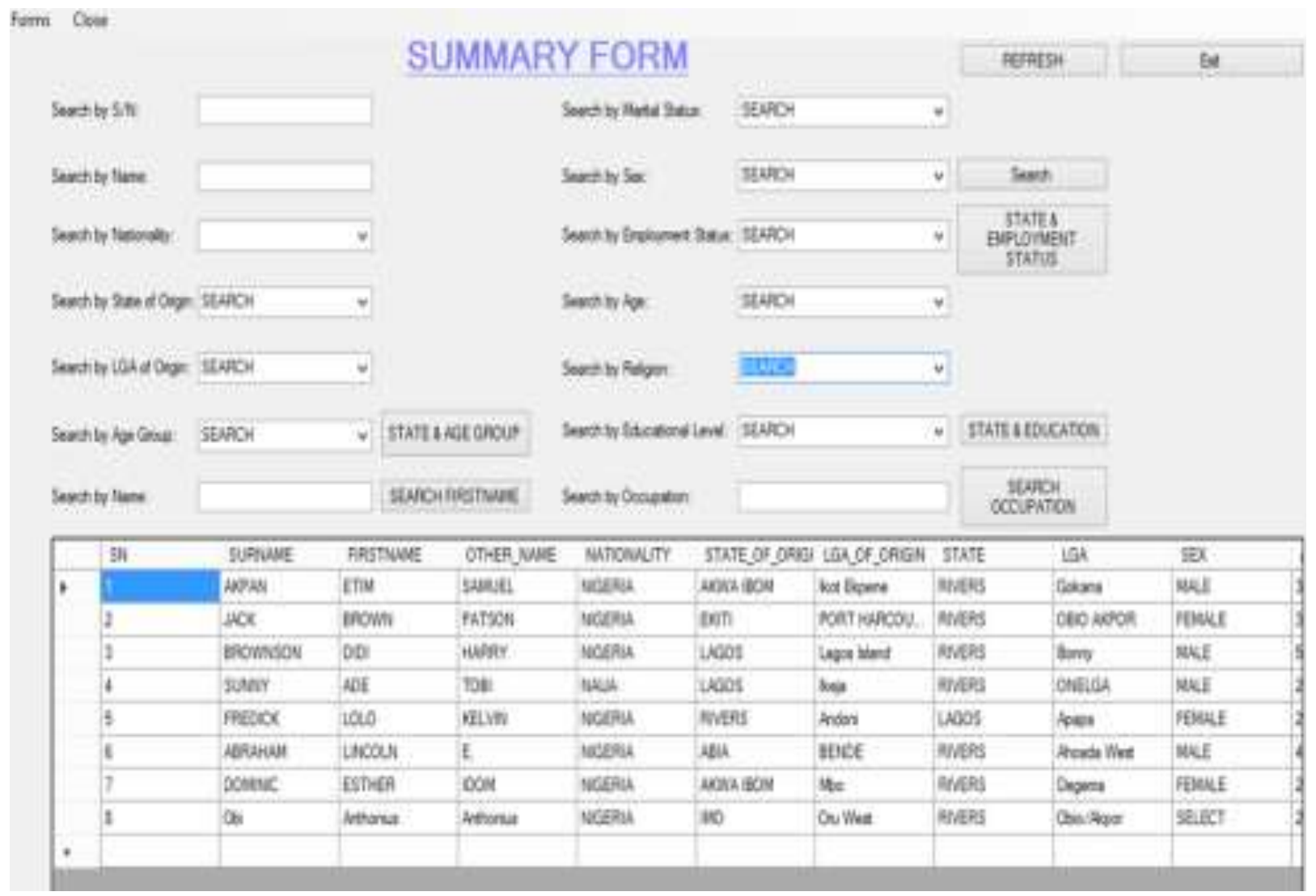

Fig 12: Summary Form

Graphical analysis of collated census results is done via the graphical chart page. Analysis is presented using both bar and pie charts. Analysis based on employment, sex and other are displayed. Figure 20 show the graphical chart displayed.

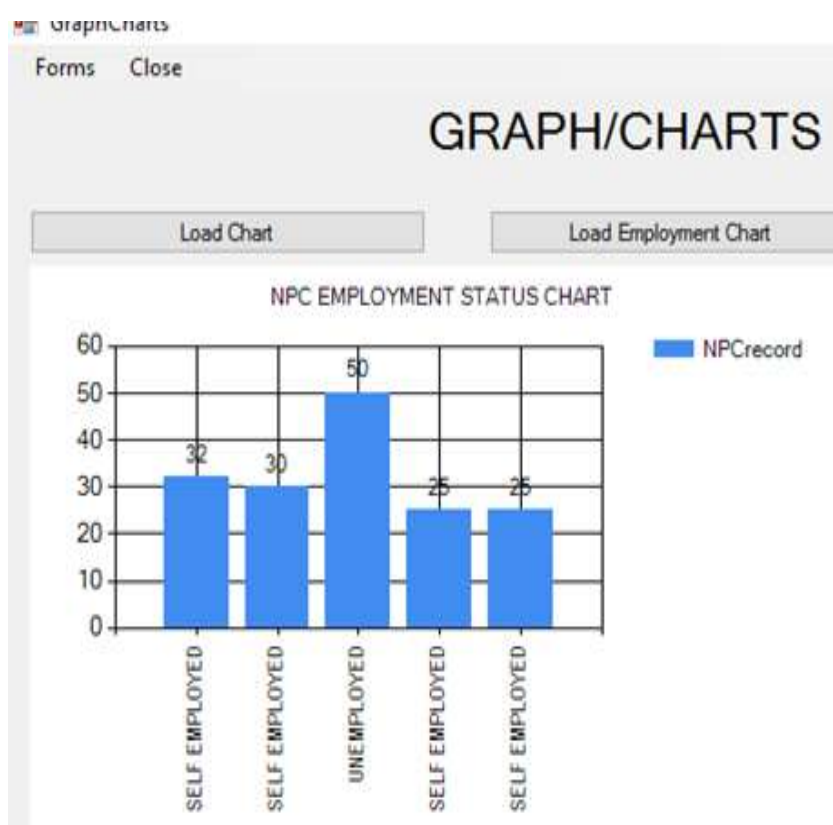

DATE: Thurgday, September 28.2017 D-

Fig 13: Graphical chart page 


\section{CONCLUSION}

A model of a Computerized Electronic Census Enumeration Platform (CECEP) leveraging on Biometric Encryption visà-vis Biometric key binding on finger prints has been developed and tested. The link between the finger print scanner module, the software interface and the database has also been validated. This model has been able to minimize the vulnerabilities associated with the conventional census enumeration schemes by fusing biometrics with cryptography and also using encryption schemes. Thisplatform is able to analyze the population census enumeration data and present charts for the analysis and national planning. It is therefore imperative to employ the computerized electronic census enumeration method as the answer and solution to the census problems encountered over the years in several nations of the world, because it eliminates most of the challenges accompanying the older methods.

\section{REFERENCES}

[1]. Baffour, B., King, T. and Valente, P. (2013). "The Modern Census: Evolution, Examples and Evaluation. International Statistical Review, 81: 407 - 425. Doi:10.1111/insr.12036.

[2]. Olugbenga Oluwagbemi, Maria Keshinro and Charles K. Ayo, (2011). "Design and Implementation of a Secured Census Information Management System". Egyptian Computer Science Journal Vol. 35 No.1 Jan2011. Pp. 2-10.

[3]. Waziri, U., Dan, J., Danjuma, S., Usman, M. J. and Aliyu, A. (2014), "Online Integrated Information System For Demography In Nigeria Based On Browser-Server Structure", International Journal Of Scientific \& Technology Research Volume 3, Issue 2, FEBRUARY 2014 ISSN 2277861680 IJSTR@2014 www.ijstr.org.

[4]. Vijayaraj, A. and DineshKumar, P. (2010) "Design and Implementation of Census Data collection System using PDA", International Journal of Computer Applications, Vol. 9, No. 9, $0975-8887$.

[5]. Bruno, M., Giacummo, M., Silipo, M. and Vaste, G. (2012), "A Web-based Management System for Addressing Census Complexity: The Italian Experience. Italian Statistical Institute.

[6]. Haug, W. and Buscher, M. (2000),'E-census, The Swiss Census 2000 0n the internet" INSEE/EUOSTAT Workshop Censuses beyond 2001, Paris, November 20 - 21, 2000.

[7]. Owuye, T. F., Awoyelu, I. O. and Bamiwuye, S. O. (2017), "Development of a Multimodal Biometric Model for Population Census" American Journal of Signal Processing, 7(1): 25-37 DOI: 10.5923/j.ajsp.20170701.03.

[8].Eniayejuni, Anthony T. and Agoyi Mary (2009)," A Biometrics Approach to Population Census and National Identification in Nigeria: A Prerequisite for Planning and Development", Asian Transactions on Basic \& Applied Sciences (ATBAS ISSN: 2221-4291) Volume 01 Issue 05 Nov 2011 ATBAS-80121059@Asian-Transactions 60.

[9]. Eze, G. C. (2009). "The role of satellite remote sensing data and GIS in population census and management in Nigeria: A case study of enumeration areas in Enugu,
Nigeria."Scientific Research and Essay, Vol.4, Is. 8, pp. 763-672.

[10]. Patel, M. B., Inchrge -Patel, R. B. and Patel, A. R. (2012),"Components of Fingerprint Biometric System" International Journal of Engineering Research and Technology(IJERT), ISSN 2278 - 0181, Vol. 1. Issue 3. 